\title{
Factors Associated with Mental Health Results among Workers with Income Losses Exposed to COVID-19 in China
}

\author{
Xin Li, Peixin Lu, Lianting Hu, Tianhui Huang and Long Lu* \\ School of Information Management, Wuhan University, Wuhan 430072, China; XinLi2020@whu.edu.cn (X.L.); \\ Lupx@whu.edu.cn (P.L.); LiantingHu@whu.edu.cn (L.H.); TianhuiHuang@whu.edu.cn (T.H.) \\ * Correspondence: lulong@whu.edu.cn
}

Received: 5 June 2020; Accepted: 31 July 2020; Published: 4 August 2020

\begin{abstract}
The outbreak and worldwide spread of COVID-19 has resulted in a high prevalence of mental health problems in China and other countries. This was a cross-sectional study conducted using an online survey and face-to-face interviews to assess mental health problems and the associated factors among Chinese citizens with income losses exposed to COVID-19. The degrees of the depression, anxiety, insomnia, and distress symptoms of our participants were assessed using the Chinese versions of the Patient Health Questionnaire-9 (PHQ-9), the Generalized Anxiety Disorder-7 (GAD-7), the Insomnia Severity Index-7 (ISI-7), and the revised 7-item Impact of Event Scale (IES-7) scales, respectively, which found that the prevalence rates of depression, anxiety, insomnia, and distress caused by COVID-19 were $45.5 \%, 49.5 \%, 30.9 \%$, and $68.1 \%$, respectively. Multivariable logistic regression analysis was performed to identify factors associated with mental health outcomes among workers with income losses during COVID-19. Participants working in Hubei province with heavy income losses, especially pregnant women, were found to have a high risk of developing unfavorable mental health symptoms and may need psychological support or interventions.
\end{abstract}

Keywords: COVID-19; depression; anxiety; insomnia; distress; income losses

\section{Introduction}

At the end of December 2019, the Chinese city of Wuhan reported a novel pneumonia caused by coronavirus disease 2019 (COVID-19), an infectious disease caused by an acute severe respiratory syndrome coronavirus, which is rapidly spreading both domestically and internationally [1,2]. On 30 January 2020, the World Health Organization (WHO) held an emergency meeting and declared the worldwide COVID-19 outbreak a public health emergency of international concern [3]. The emergence and rapid increase in the number of COVID-19 cases has posed and continues to pose complex challenges for global research, public health, and medical communities [4,5]. As of 1 June 2020, there were more than 6.15 million confirmed cases of COVID-19 across more than 215 countries and regions, including more than 372,130 deaths.

With the rapid spread of COVID-19, the local government in Wuhan immediately adopted a city closure policy, encouraging citizens to work at home and teach online, and shut down non-essential services to mitigate the impact and risks of the disease. Then, the governments of other provinces with low numbers of infected people in China and many other countries around the world entered states of emergency for the health response and issued a series of policies, including ordering citizens (regardless of having symptoms of infection or not) to self-isolate at home, and maintaining social distance from other people. However, concerns have arisen about the potential psychological impact of these measures [6-8]. 
Studies proved that COVID-19 has caused a high prevalence of mental health problems in China [8-12] and other countries around the world [13-16]. Some researchers have attempted to understand the outbreak of this novel coronavirus from a global health perspective [17-19]. However, most studies focused on the psychological effects of people who were infected with COVID-19, medical workers, or people in specific regions $[10-15,20]$. Studies showed that the economic impact caused by severe acute respiratory syndrome (SARS) will produce psychological morbidities in individuals who are directly or indirectly exposed to life-threatening situations [21]. The occurrence of such psychological morbidities among workers can impact their daily functions and lead to immediate economic and physiological consequences, such as lost job productivity, depression, and anxiety [22,23].

To the best of our knowledge, no previous study focused on mental health problems among people with income losses caused by COVID-19. To address this gap, the aim of our study was to evaluate the mental health of Chinese workers with income losses exposed to COVID-19 by quantifying the degrees of depression, anxiety, insomnia, and distress, and analyze the potential risk factors related to these symptoms. In this study, besides age, sex and other demographic characteristics, participants from Hubei province and outside Hubei province were taken as the research objects for comparison of regional differences. The ultimate goal of this study was to assess the mental health burden of people with income losses during COVID-19 and to provide guidance for the promotion of mental well-being among this population.

\section{Materials and Methods}

\subsection{Design and Participants}

This was a cross-sectional study conducted using an online survey and face-to-face interviews to assess mental health problems and their associations with income losses among Chinese citizens who were exposed to coronavirus disease 2019 (COVID-19) from 25 April to 9 May 2020.

Eligibility criteria included (i) currently living in China, (ii) aged 18 years or older, and (iii) with income losses caused by COVID-19. Participants were encouraged to participate in online surveys or complete offline questionnaires. A total of 421 of 600 contacted individuals completed the survey for a participation rate of $70.2 \%$, and 23 people with no loss of income were excluded from the study. The final sample included 398 respondents, with a response rate of $66.3 \%$. This study was approved by the Ethics Committee and Institutional Review Board of Wuhan University, Wuhan, China (Ref: 20200411), and conducted in accordance with the ethical guidelines of the Declaration of Helsinki of the World Medical Association. All data were deidentified before being provided to the investigators. Consent from each participant was obtained at the beginning of the survey.

\subsection{Questionnaire}

The questionnaire consisted of 37 factors to record demographic indicators and symptoms of depression, anxiety, insomnia, and distress caused by COVID-19 of the participants (See Appendix A).

\subsubsection{Covariates}

The following demographic data were included in this study: sex (male or female), age (18-25, 26-30, 31-40 and $>40$ years old categories), educational level (<undergraduate, college, masters, and higher), marital status (married and other including unmarried, widowed, and divorced), working location (Hubei province, and outside Hubei province), loss of income caused by COVID-19 (light, middle, or heavy, $>0 \%$ to $25 \%, 25-50 \%$, and $>50 \%$ less than pre-epidemic income, respectively), and place of residence (urban or rural).

\subsubsection{Mental Health Problems}

Mental disorders, including depression, anxiety, insomnia, and distress, caused by COVID-19 were assessed in our study by Chinese versions of validated measurement tools [24-27]: the Patient 
Health Questionnaire-9 (PHQ-9; the total score ranged from 0 to 27) [24], the Generalized Anxiety Disorder-7 (GAD-7; the total score ranged from 0 to 21) [25], the Insomnia Severity Index-7 (ISI-7; the total score ranged from 0 to 28) [26], and the revised 7-item Impact of Event Scale (IES-7; the total score ranged from 0 to 28) [27]. The response options are: $3=$ nearly every day, $2=$ more than half the days, $1=$ several days, and $0=$ not at all for PHQ- 9 and GAD-7; $4=$ always, $3=$ often, $2=$ sometimes, $1=$ rare, and $0=$ never for ISI-7 and IES-7. The total scores of these survey scales are interpreted as follows: PHQ-9, extremely severe (22-28), severe (15-21), moderate (10-14), mild (5-9), and normal (0-4) depression; GAD-7, severe (15-21), moderate (10-14), mild (5-9), and normal (0-4) anxiety; ISI-7, severe (22-28), moderate (15-21), subthreshold (8-14), normal (0-7) insomnia; and IES-7 severe (22-28), moderate (15-21), subthreshold (8-14), and normal (0-7) distress. The cutoff score for detecting possible major symptoms of depression, anxiety, insomnia, and distress caused by COVID-19 are 10, 10,15 , and 15, respectively. A higher score indicates participants with greater self-reported severe symptoms [24-27].

The psychometric properties and internal reliabilities of the 4 scales have been previously confirmed in Chinese populations [24-27]. In [24], statistical tests were performed to determine the reliability and validity of PHQ-9. Results showed that the internal consistency value of PHQ-9 was 0.854 and the test-retest reliability value of PHQ-9 was 0.873 , proving the PHQ-9 is a valid and reliable tool to evaluate depression in Chinese people. He [25] tested the reliability and validity of Chinese version of GAD-7. The results show that the Cronbach ' $\alpha$ coefficient of GAD-7 is 0.898, and the test-retest reliability coefficient is 0.856 , proving the Chinese version of GAD-7 has good reliability and validity in the application of evaluating anxiety. Doris S.F. Yu [26] tested the reliability and validity of Chinese version of ISI-7, finding that Cronbach's alpha of the Chinese version of the ISI-7 was 0.81, with item-to-total correlations in the range of 0.34-0.67. In [27], Chan reported that the Cronbach ' $\alpha$ coefficient of IES-R is 0.89 , which proved the IES-R is a valid and reliable tool to evaluate distress among Chinese people. In our study, the Cronbach's alpha coefficient of our questionnaire is 0.97. The Cronbach's alpha coefficients of the Chinese versions of PHQ-9, GAD-7, ISI-7 and IES-7 were 0.920, $0.945,0.879$ and 0.909 , respectively.

\subsection{Statistical Analysis}

First, we used descriptive statistics to describe the socio-demographic characteristics of these participants. Second, the prevalence rates of depression (PHQ-9 score $\geq 5$ ), anxiety (GAD-7 score $\geq 5$ ), insomnia (ISI-7 score $\geq 8$ ), and distress (IES-7 score $\geq 8$ ) were estimated. Finally, multivariable logistic regression models were used to explore factors associated with depression, anxiety, insomnia, and distress among workers with income losses exposed to COVID-19 in China, and the associations between risk factors and outcomes are presented as adjusted odds ratios (aORs) with a 95\% confidence interval (CI), after adjustment for confounders, including sex, age, marital status, educational level, working position, place of residence, degrees of income losses. Data analysis was performed by SPSS statistical software (version 25.0, IBM Corp., Armonk, NY, USA,), with $p$-values $<0.05$ indicating statistical significance. The significance level was set at $\alpha=0.05$, and all tests were two-tailed.

\section{Results}

\subsection{Demographic Characteristics}

As shown in Table 1, the proportion of men to women was close, at $50.5 \%$ and $49.5 \%$, respectively, and the proportion of marital status (recoded into married and other including unmarried, widowed, and divorced) was similar to that of sex, at $49.5 \%$ and $50.5 \%$, respectively. We classified their income losses caused by COVID-19 as one of the demographic variables. Response options were slightly affected ( $>0 \%$ to $25 \%)$, moderately affected (25-50\%), and heavily affected $(>50 \%)$. Table 1 shows that the proportions of light, middle, and heavy income loss (>0\% to $25 \%, 25-50 \%$, and $>50 \%$ lower income than pre-epidemic income, respectively) caused by COVID- 19 were $33.9 \%, 17.6 \%$, and $48.5 \%$, 
respectively. As Hubei was most severely affected province by COVID-19 in China, all 398 participants were grouped by their geographic location. The proportions in Hubei province, and places outside Hubei province were $44.2 \%$, and $55.8 \%$, respectively. Most of these participants were aged from 26 to 40 years, lived in urban areas, and had a college degree or above.

Table 1. Demographic and occupational characteristics of participants.

\begin{tabular}{|c|c|c|c|c|}
\hline \multirow{3}{*}{ Demographics } & \multirow{2}{*}{ Total (\%) } & \multicolumn{3}{|c|}{ Income Losses Caused by COVID-19 } \\
\hline & & Light & Middle & Heavy \\
\hline & $398(100 \%)$ & $135(33.9 \%)$ & $70(17.6 \%)$ & $193(48.5 \%)$ \\
\hline \multicolumn{5}{|l|}{ Age (years) } \\
\hline $18-25$ & 78 (19.6\%) & $31(7.8 \%)$ & $10(2.5 \%)$ & 37 (9.3\%) \\
\hline $26-30$ & 127 (31.9\%) & 40 (10.1\%) & $14(3.5 \%)$ & $73(18.3 \%)$ \\
\hline $31-40$ & $145(36.4 \%)$ & 44 (11.1\%) & 38 (9.5\%) & $63(15.8 \%)$ \\
\hline$>40$ & $48(12.1 \%)$ & $20(5.0 \%)$ & $8(2.0 \%)$ & $20(5.0 \%)$ \\
\hline \multicolumn{5}{|l|}{ Sex } \\
\hline Male & $201(50.5 \%)$ & $67(16.8 \%)$ & $39(9.8 \%)$ & $95(23.9 \%)$ \\
\hline Female & $197(49.5 \%)$ & $68(17.1 \%)$ & $31(7.8 \%)$ & $98(24.6 \%)$ \\
\hline \multicolumn{5}{|l|}{ Education } \\
\hline$<$ Undergraduate & $110(27.6 \%)$ & $22(5.5 \%)$ & $17(4.3 \%)$ & $71(17.8 \%)$ \\
\hline College & $180(45.2 \%)$ & $66(16.6 \%)$ & $42(10.6 \%)$ & $72(18.1 \%)$ \\
\hline$>$ Master & $108(27.1 \%)$ & $47(11.8 \%)$ & $11(2.8 \%)$ & $50(12.6 \%)$ \\
\hline \multicolumn{5}{|l|}{ Marital Status } \\
\hline Married & $197(49.5 \%)$ & $72(18.1 \%)$ & $32(8.0 \%)$ & $93(23.4 \%)$ \\
\hline Not married & $201(50.5 \%)$ & $63(15.8 \%)$ & $38(9.5 \%)$ & $100(25.1 \%)$ \\
\hline \multicolumn{5}{|l|}{ Working Location } \\
\hline Hubei Province & $176(44.2 \%)$ & $43(10.8 \%)$ & $30(7.5 \%)$ & $103(25.9 \%)$ \\
\hline Others & $222(55.8 \%)$ & $92(23.1 \%)$ & $40(10.1 \%)$ & $90(22.6 \%)$ \\
\hline \multicolumn{5}{|l|}{ Residence } \\
\hline Urban & $298(74.9 \%)$ & $116(29.1 \%)$ & $51(12.8 \%)$ & $131(32.9 \%)$ \\
\hline Rural & $100(25.1 \%)$ & $19(4.8 \%)$ & $19(4.8 \%)$ & $62(15.6 \%)$ \\
\hline
\end{tabular}

\subsection{Prevalence Rates of Mental Symptoms and Associated Factors}

Generally consistent with the existing COVID-19 research results [8-10], the prevalence rates of our participants who had symptoms of depression, anxiety, insomnia, and distress cause by COVID-19 were $45.5 \%, 49.5 \%, 30.9 \%$, and $68.1 \%$, respectively. As shown in Table 2, multivariable logistic regression analyses showed that, after controlling for covariates, the adjusted odds of depression, anxiety, insomnia and distress were lower among participants who under 30 years (e.g., depression among participants aged 26-30 years: OR $=0.228,95 \% \mathrm{CI}$ : 0.097-0.535, $p<0.001$; depression among participants aged 18-25 years: $\mathrm{OR}=0.187,95 \% \mathrm{CI}: 0.072-0.489, p<0.001)$ compared with who aged over 40 years, and greater among those working in Hubei province (e.g., depression: OR = 2.647, 95\% CI: $1.662-4.217, p<0.001)$ than outside Hubei province. For the population whose income was heavily affected by COVID-19, they were prone to experiencing mental symptoms of depression, anxiety, and insomnia (e.g., depression among participants with light income losses: OR =0.215, 95\% CI: 0.124-0.371, $p<0.001$ ). Those from urban area had lower adjusted odds of depression anxiety, insomnia and distress than those from rural area (e.g., depression: OR $=0.391,95 \%$ CI: 0.226-0.675, $p=0.001)$. At the same time, being married (OR, 3.348; 95\% CI, 1.896-5.911; $p<0.001$ ) was associated with a greater risk of feeling depressed than being unmarried.

In sex statistics, we set an additional question (If you are a woman, please indicate whether you are pregnant). In this study, as shown in Table 3, multivariable logistic regression analyses showed that, after controlling for covariates, we found that pregnant women with income losses during COVID-19 were associated with a greater risk of feeling depressed and anxiety (depression: OR $=2.956,95 \% \mathrm{CI}$ : 1.208-7.229, $p=0.018$; anxiety: OR $=3.146,95 \% \mathrm{CI}: 1.217-6.133, p=0.018)$ than unpregnant women (Table 3). 
Table 2. Prevalence of depression and associated factors.

\begin{tabular}{|c|c|c|c|c|}
\hline \multirow{2}{*}{ Variable } & \multirow{2}{*}{ Prevalence } & \multirow{2}{*}{ aOR $(95 \% \mathrm{CI})$} & \multicolumn{2}{|c|}{$p$-Value } \\
\hline & & & Category & Overall \\
\hline \multicolumn{5}{|c|}{ PHQ-9, depression symptoms } \\
\hline Overall & $181 / 398(45.5 \%)$ & & & \\
\hline \multicolumn{5}{|l|}{ Age (years) } \\
\hline $18-25$ & $32 / 78(41.0 \%)$ & $0.187(0.072,0.489)$ & 0.001 & \multirow{4}{*}{$<0.001$} \\
\hline $26-30$ & $45 / 127(35.4 \%)$ & $0.228(0.097,0.535)$ & 0.001 & \\
\hline $31-40$ & $69 / 145(47.5 \%)$ & $0.597(0.275,1.294)$ & 0.191 & \\
\hline$>40$ & $35 / 48(72.9 \%)$ & 1 (Reference) & NA & \\
\hline \multicolumn{5}{|l|}{ Sex } \\
\hline Male & $93 / 201(46.3 \%)$ & $1.013(0.641,1.605)$ & 0.956 & \multirow{2}{*}{0.956} \\
\hline Female & $88 / 197(44.7 \%)$ & 1 (Reference) & NA & \\
\hline \multicolumn{5}{|l|}{ Education } \\
\hline$<$ Undergraduate & $67 / 110(60.9 \%)$ & $1.640(0.846,3.178)$ & 0.143 & \multirow{3}{*}{0.336} \\
\hline College & $76 / 180(42.2 \%)$ & $1.292(0.741,2.252)$ & 0.366 & \\
\hline$>$ Master & $38 / 108(35.2 \%)$ & 1 (Reference) & NA & \\
\hline \multicolumn{5}{|l|}{ Marital Status } \\
\hline Married & 113/197 (57.4\%) & $3.348(1.896,5.911)$ & $<0.001$ & \multirow{2}{*}{$<0.001$} \\
\hline Not married & $68 / 201(33.8 \%)$ & 1 (Reference) & NA & \\
\hline \multicolumn{5}{|l|}{ Working Location } \\
\hline Hubei Province & $108 / 176(61.4 \%)$ & $2.647(1.662,4.217)$ & $<0.001$ & \multirow{2}{*}{$<0.001$} \\
\hline Others & $73 / 222(32.9 \%)$ & 1 (Reference) & NA & \\
\hline \multicolumn{5}{|l|}{ Residence } \\
\hline Urban & $112 / 298(37.6 \%)$ & $0.391(0.226,0.675)$ & 0.001 & \multirow[b]{2}{*}{0.001} \\
\hline Rural & $69 / 100(69.0 \%)$ & 1 (Reference) & NA & \\
\hline \multicolumn{5}{|l|}{ Income losses caused by } \\
\hline \multicolumn{5}{|l|}{ COVID-19 } \\
\hline Light & $32 / 135(23.7 \%)$ & $0.215(0.124,0.371)$ & $<0.001$ & \multirow{3}{*}{$<0.001$} \\
\hline Middle & $30 / 70(49.2 \%)$ & $0.429(0.231,0.797)$ & 0.007 & \\
\hline Heavy & $119 / 193(61.7 \%)$ & 1 (Reference) & NA & \\
\hline
\end{tabular}

Table 2 lists the detailed results of PHQ-9 from multivariable logistic regression analysis; the results for the other scales are presented in Supplementary Materials (Tables S1-S3). Abbreviations: NA = Not Available; aOR: adjusted odds ratio; CI: confidence interval. PHQ-9: the Patient Health Questionnaire-9.

Table 3. Prevalence rates of mental symptoms and associated factors in female cohort.

\begin{tabular}{|c|c|c|c|c|}
\hline \multirow{2}{*}{ Variable } & \multirow{2}{*}{ Prevalence } & \multirow{2}{*}{ aOR $(95 \% \mathrm{CI})$} & \multicolumn{2}{|c|}{$p$-Value } \\
\hline & & & Category & Overall \\
\hline \multicolumn{5}{|c|}{ PHQ-9, depression symptoms } \\
\hline \multicolumn{5}{|l|}{ Pregnancy } \\
\hline Pregnant & $29 / 45(64.4 \%)$ & $2.956(1.208,7.229)$ & 0.018 & \multirow{2}{*}{0.018} \\
\hline Not pregnant & $64 / 152(42.1 \%)$ & 1 (Reference) & NA & \\
\hline \multicolumn{5}{|c|}{ GAD-7, anxiety symptoms } \\
\hline \multicolumn{5}{|l|}{ Pregnancy } \\
\hline Pregnant & $37 / 45(82.8 \%)$ & $3.146(1.217,6.133)$ & 0.018 & \multirow{2}{*}{0.018} \\
\hline Not pregnant & $75 / 152(49.3 \%)$ & 1 (Reference) & NA & \\
\hline \multicolumn{5}{|c|}{ ISI, insomnia symptoms } \\
\hline \multicolumn{5}{|l|}{ Pregnancy } \\
\hline Pregnant & $24 / 45(53.3 \%)$ & $1.578(0.654,3.804)$ & 0.601 & \multirow{2}{*}{0.601} \\
\hline Not pregnant & $45 / 152(29.6 \%)$ & 1 (Reference) & NA & \\
\hline \multicolumn{5}{|c|}{ IES-7, distress symptoms } \\
\hline \multicolumn{5}{|l|}{ Pregnancy } \\
\hline Pregnant & $38 / 45(84.4 \%)$ & $1.605(0.595,4.328)$ & 0.350 & \multirow{2}{*}{0.350} \\
\hline Not pregnant & $102 / 152(67.1 \%)$ & 1 (Reference) & NA & \\
\hline
\end{tabular}

Abbreviations: NA = Not Available; aOR: adjusted odds ratio; CI: confidence interval. PHQ-9: the Patient Health Questionnaire-9; GAD-7: the Generalized Anxiety Disorder-7; ISI-7: the Insomnia Severity Index-7; IES-7: the revised 7-item Impact of Event Scale. 


\subsection{Prevalence Rates of Severe Mental Symptoms and Associated Factors}

According to Lai, J et al. [10], the cutoff scores for detecting possible major symptoms of depression, anxiety, insomnia, and distress caused by COVID-19 are 10,10,15, and 15, respectively. Thus, the prevalence rates of our participants who had severe mental symptoms of depression, anxiety, insomnia, and distress were $19.1 \%, 21.9 \%, 7.8 \%$, and $25.9 \%$, respectively. Similar to findings regarding prevalence of mental symptoms, as shown in Table 4, multivariable logistic regression analyses showed that, after controlling for covariates, the adjusted odds of severe symptoms of depression, anxiety, and distress were lower among participants who aged 26-30 years (e.g., severe depression: OR $=0.243,95 \%$ CI: $0.091-0.645, p=0.005)$ compared with who aged over 40 years, greater among those with heavy income losses than light and middle income losses (e.g., severe depression among participants with light income losses: $\mathrm{OR}=0.246,95 \%$ CI: $0.121-0.502, p<0.001)$, and lower among those from urban area than those from rural area (e.g., severe depression: $\mathrm{OR}=0.337,95 \%$ CI: $0.185-0.615, p<0.001$ ). For those working in Hubei province, they were more prone to experiencing severe mental symptoms of anxiety and distress than those working outside Hubei province.

Table 4. Prevalence of severe depression and associated factors.

\begin{tabular}{|c|c|c|c|c|}
\hline \multirow{2}{*}{ Variable } & \multirow{2}{*}{$\begin{array}{l}\text { No. of Severe Cases/ } \\
\text { No. of Total Cases (\%) }\end{array}$} & \multirow{2}{*}{ aOR $(95 \% \mathrm{CI})$} & \multicolumn{2}{|c|}{$p$-Value } \\
\hline & & & Category & Overall \\
\hline \multicolumn{5}{|c|}{ PHQ-9, depression symptoms } \\
\hline Overall & 76/398 (19.1\%) & & & \\
\hline \multicolumn{5}{|l|}{ Age (years) } \\
\hline $18-25$ & $15 / 78(19.2 \%)$ & $0.404(0.139,1.175)$ & 0.096 & \multirow{4}{*}{0.042} \\
\hline $26-30$ & $16 / 127(12.6 \%)$ & $0.243(0.091,0.645)$ & 0.005 & \\
\hline $31-40$ & $32 / 145(22.1 \%)$ & $0.450(0.189,1.070)$ & 0.071 & \\
\hline$>40$ & $13 / 48(27.1 \%)$ & 1 (Reference) & NA & \\
\hline \multicolumn{5}{|l|}{ Sex } \\
\hline Male & 37/201 (18.4\%) & $0.864(0.500,1.495)$ & 0.601 & \multirow{2}{*}{0.601} \\
\hline Female & 39/197 (19.8\%) & 1 (Reference) & NA & \\
\hline \multicolumn{5}{|l|}{ Education } \\
\hline$<$ Undergraduate & $38 / 110(34.5 \%)$ & $1.369(0.646,2.899)$ & 0.413 & \multirow{3}{*}{0.060} \\
\hline College & $20 / 180(11.1 \%)$ & $0.590(0.285,1.219)$ & 0.154 & \\
\hline$>$ Master & 18/108 (16.7\%) & 1 (Reference) & NA & \\
\hline \multicolumn{5}{|l|}{ Marital Status } \\
\hline Married & 38/197 (19.3\%) & $1.539(0.826,2.868)$ & 0.173 & \multirow{2}{*}{0.173} \\
\hline Not married & $38 / 201(18.9 \%)$ & 1 (Reference) & NA & \\
\hline \multicolumn{5}{|l|}{ Working Location } \\
\hline Hubei Province & $42 / 176(23.9 \%)$ & $1.085(0.619,1.903)$ & 0.776 & \multirow{2}{*}{0.776} \\
\hline Others & $34 / 222(15.3 \%)$ & 1 (Reference) & NA & \\
\hline \multicolumn{5}{|l|}{ Residence } \\
\hline Urban & 40/298 (13.4\%) & $0.337(0.185,0.615)$ & $<0.001$ & \multirow{2}{*}{$<0.001$} \\
\hline Rural & $36 / 100(36.0 \%)$ & 1 (Reference) & NA & \\
\hline \multicolumn{5}{|c|}{ Income losses caused by COVID-19 } \\
\hline Light & $12 / 135(8.9 \%)$ & $0.246(0.121,0.502)$ & $<0.001$ & \multirow{3}{*}{$<0.001$} \\
\hline Middle & $3 / 70(4.3 \%)$ & $0.086(0.025,0.291)$ & $<0.001$ & \\
\hline Heavy & $61 / 193(31.6 \%)$ & 1 (Reference) & NA & \\
\hline
\end{tabular}

Table 4 lists the detailed results of PHQ-9 from multivariable logistic regression analysis; the results for the other scales are presented in Supplementary Materials (Tables S4-S6). Abbreviations: NA = Not Available; aOR: adjusted odds ratio; CI: confidence interval. PHQ-9: the Patient Health Questionnaire-9. 


\section{Discussion}

We enrolled 398 respondents and found a high prevalence of mental health symptoms among workers with income losses caused by COVID-19 in China. This latest national sample indicated the prevalence rates of any disorder (excluding dementia), anxiety disorders, and depressive disorders were $16.6 \%, 7.6 \%$, and $6.9 \%$ in China, respectively. Compared with national data, we found much higher prevalence rates of participants with symptoms of depression, anxiety, insomnia, and distress caused by COVID-19, at $45.5 \%, 49.5 \%, 30.9 \%$, and $68.1 \%$, respectively. Our findings are consistent with those of previous COVID-19 studies, including a study in mainland China that found that the prevalence of depression as measured during the COVID-19 pandemic was 48.3\% [8] and a study in Hong Kong that found that the prevalence of depression caused by COVID-19 was 49.8\% [9].

Mental disorders, including depression, anxiety, insomnia, and distress, caused by COVID-19 were assessed in our study by Chinese versions of validated measurement tools [24-27]: PHQ-9, GAD-7, and ISI-7. In our study, the Cronbach's alpha coefficient of our questionnaire is 0.97 . The Cronbach's alpha coefficients of the Chinese versions of PHQ-9, GAD-7, ISI-7 and IES-7 were 0.920, 0.945, 0.879 and 0.909 , respectively, proving these scales have good reliabilities and validities in the application of evaluating mental disorders among Chinese worker with income losses. By reviewing the literature, we found that these Chinese scales are widely used in the study of psychological problems. Especially recently, these four scales have been used to study COVID-19. For example, researchers used them to assess the magnitude of mental health outcomes among healthcare workers treating patients exposed to COVID-19 in China [10], PHQ-9 and GAD-7 were used to evaluate depression and anxiety in Hong Kong during the COVID-19 pandemic [9], and GAD-7 was used to assess the prevalence of mental health problems and examine their association with social media exposure [8].

In this study, besides age, sex and other demographic characteristics, participants from Hubei province and outside Hubei province were taken as the research objects for comparison of regional differences. The proportions of respondents from Hubei province and places outside Hubei province were $44.2 \%$ and $55.8 \%$, respectively. The proportions of light, middle, and heavy losses of income ( $>0$ to $25 \%, 25-50 \%$, and $>50 \%$ less income than pre-epidemic levels, respectively) caused by COVID-19 were $33.9 \%, 17.6 \%$, and $48.5 \%$, respectively. Most of these participants were aged from 26 to 40 years, lived in urban areas, and had a college degree or above. We found that workers with heavy income losses caused by COVID-19 reported more symptoms of depression, anxiety, and insomnia. Compared with participants outside Hubei province, those in Hubei province reported higher scores on all four scales. The prevalence rates of our participants who had severe mental symptoms of depression, anxiety, insomnia, and distress were $19.1 \%, 21.9 \%, 7.8 \%$, and $25.9 \%$, respectively. Our findings further indicated that pregnant women scored higher than non-pregnant women on PHQ-9 and GAD-7 measuring symptoms of depression and anxiety. These findings are consistent with the previous studies' findings that exposure to a public health emergency can cause mental health problems.

This study has several limitations. First, it was limited in scope. Almost half of the participants $(44.2 \%)$ were from Hubei province, limiting the generalization of our findings to less affected regions. This survey was mainly conducted online, so some respondent bias, such as few elder citizens' participation, may have affected the results. Second, the survey was conducted over two weeks and lacked longitudinal follow-up. It was hard to determine whether the mental health symptoms of workers with income losses could become more severe, so the long-term psychological implications of this population are worth further investigation. Last, although the response rate of this study was $70.1 \%$, response bias may still exist if the non-respondents were either too stressed to respond or not at all stressed and therefore not interested in this survey.

\section{Conclusions}

In conclusion, our findings showed that relatively high prevalence rates of symptoms of depression, anxiety, insomnia, and distress were caused by COVID-19. The prevalence of mental health problems among workers caused by COVID-19 in China is high, especially those working in Hubei province 
with heavy income losses. In addition, pregnant women with income losses were associated with a greater risk of feeling depressed and anxiety than other women, and may need psychological support or interventions. These results further indicate that the long-term psychological implications of this population are worth further investigation.

Supplementary Materials: The following are available online at http://www.mdpi.com/1660-4601/17/15/5627/s1, Table S1: Prevalence of anxiety and associated factors, Table S2: Prevalence of insomnia and associated factors, Table S3: Prevalence of distress and associated factors, Table S4: Prevalence of severe anxiety and associated factors, Table S5: Prevalence of severe insomnia and associated factors, Table S6: Prevalence of severe distress and associated factors.

Author Contributions: Conceptualization, X.L.; data curation, X.L. and P.L.; software, X.L. and L.H.; validation, X.L., P.L., T.H. and L.H.; investigation, X.L., T.H. and P.L.; writing-review and editing, X.L., and L.L.; visualization, X.L.; supervision, L.L.; project administration L.L. All authors have read and agreed to the published version of the manuscript.

Funding: This research was funded by National Natural Science Foundation of China [No. 61772375, 18ZDA325]; Hubei Provincial Natural Science Foundation of China [No. 2019CFA025]; National Key R\&D Program of China (2019YFC010167); and Independent Research Project of School of Information Management Wuhan University (No: 413100032).

Conflicts of Interest: The authors declare no conflicts of interest.

\section{Appendix A}

The questionnaire consisted of 37 questions to record demographic indicators and symptoms of depression, anxiety, insomnia, and distress of all participants.

1. Demographic data

The following demographic data were included in this study: sex (male or female), age (18-25, 26-30, 31-40, or $>40$ years categories), educational level (<undergraduate, college, masters, or higher), marital status (recoded into married or other including unmarried, widowed, and divorced), working location (Hubei province or outside Hubei province), loss of income caused by COVID-19 (light, middle, and heavy, being $>0$ to $25 \%, 25-50 \%$, and $>50 \%$ less income than the pre-epidemic level, respectively), and place of residence (urban or rural).

\section{Mental Health Scales}

The English versions of the PHQ-9, GAD-7, ISI-7, and IES-R-7 scales were used in this study to measure the degree of symptoms of depression, anxiety, insomnia, and distress of our participants.

Table A1. Patient Health Questionnaire-9 (PHQ-9).

\begin{tabular}{|c|c|c|c|c|}
\hline Depression Problem & Not at All & Somewhat & More than Half the Days & Nearly Every Day \\
\hline Little interest or pleasure in doing things? & 0 & 1 & 2 & 3 \\
\hline Feeling down, depressed, or hopeless? & 0 & 1 & 2 & 3 \\
\hline $\begin{array}{c}\text { Trouble falling or staying asleep, or sleeping } \\
\text { too much? }\end{array}$ & 0 & 1 & 2 & 3 \\
\hline Feeling tired or having little energy? & 0 & 1 & 2 & 3 \\
\hline Poor appetite or overeating? & 0 & 1 & 2 & 3 \\
\hline $\begin{array}{c}\text { Feeling bad about yourself or that you are a failure } \\
\text { or have let yourself or your family down? }\end{array}$ & 0 & 1 & 2 & 3 \\
\hline $\begin{array}{l}\text { Trouble concentrating on things, such as reading the } \\
\text { newspaper or watching television? }\end{array}$ & 0 & 1 & 2 & 3 \\
\hline $\begin{array}{l}\text { Moving or speaking so slowly that other people } \\
\text { could have noticed? Or so fidgety or restless that } \\
\text { you have been moving a lot more than usual? }\end{array}$ & 0 & 1 & 2 & 3 \\
\hline $\begin{array}{l}\text { Thoughts that you would be better off dead, or } \\
\text { thoughts of hurting yourself in some way? }\end{array}$ & 0 & 1 & 2 & 3 \\
\hline Total & & & & \\
\hline
\end{tabular}


Table A2. General Anxiety Disorder-7 (GAD-7).

\begin{tabular}{ccccc}
\hline Anxiety Problem & Not at All & Several & More than Half the Days & Nearly Every Day \\
\hline Feeling nervous, anxious, or on edge & 0 & 1 & 2 & 3 \\
\hline Not being able to stop or control worrying & 0 & 1 & 2 & 3 \\
\hline Worrying too much about different things & 0 & 1 & 2 & 3 \\
\hline Trouble relaxing & 0 & 1 & 2 & 3 \\
\hline Being so restless that it's hard to sit still & 0 & 1 & 2 & 3 \\
\hline Becoming easily annoyed or irritable & 0 & 1 & 2 & 3 \\
\hline $\begin{array}{c}\text { Feeling afraid as if something awful } \\
\text { might happen }\end{array}$ & 0 & 1 & & 2 \\
\hline Total & & &
\end{tabular}

Table A3. Insomnia Severity Index-7 (ISI-7).

\begin{tabular}{cccccc}
\hline Insomnia Problem & None & Mild & Moderate & Severe & Very Severe \\
\hline Difficulty falling asleep & 0 & 1 & 2 & 3 & 4 \\
\hline Difficulty staying asleep & 0 & 1 & 2 & 3 & 4 \\
\hline Problems waking up too early & 0 & 1 & 2 & 3 & 4 \\
\hline $\begin{array}{c}\text { How satisfied/dissatisfied are you with } \\
\text { your current sleep pattern? }\end{array}$ & 0 & 1 & 2 & 3 & 4 \\
\hline $\begin{array}{c}\text { How noticeable to others do you think } \\
\text { your sleep problem is in terms of } \\
\text { impairing the quality of your life? }\end{array}$ & 0 & 1 & 2 & 3 & 4 \\
\hline $\begin{array}{c}\text { How worried/ distressed are you about } \\
\text { your current sleep problem? }\end{array}$ & 0 & 1 & 2 & 3 & 4 \\
\hline $\begin{array}{c}\text { To what extent do you consider your } \\
\text { sleep problem to interfere with your } \\
\text { daily functioning currently? }\end{array}$ & 0 & 1 & 2 & & 4 \\
\hline Total & & & & 4 \\
\hline
\end{tabular}

Table A4. Revised Event Impact Scale (IES-7).

\begin{tabular}{cccccc}
\hline Distress Problem & None & Mild & Moderate & Severe & Very Severe \\
\hline It's upsetting to think about COVID-19 & 0 & 1 & 2 & 3 & 4 \\
\hline COVID-19 has affected my quality of life & 0 & 1 & 2 & 3 & 4 \\
\hline $\begin{array}{c}\text { COVID-19 has affected my } \\
\text { learning/work/income/employment }\end{array}$ & 0 & 1 & 2 & 3 & 4 \\
\hline COVID-19 has affected family/couple relations & 0 & 1 & 2 & 3 & 4 \\
\hline I dream about COVID-19 & 0 & 1 & 2 & 3 & 4 \\
\hline I try not to mention anything about COVID-19 & 0 & 1 & 2 & 3 & 4 \\
\hline I am still worried about COVID-19 & 0 & 1 & 2 & 3 \\
\hline Total & & & 4
\end{tabular}

\section{References}

1. Li, Q.; Guan, X.; Wu, P.; Wang, X.; Zhou, L.; Tong, Y.; Ren, R.; Leung, K.S.M.; Lau, E.H.Y.; Wong, J.Y.; et al. Early transmission dynamics in Wuhan, China, of novel coronavirus-infected pneumonia. N. Engl. J. Med. 2020, 382, 1199-1207. [CrossRef]

2. Zhu, N.; Zhang, D.; Wang, W.; Li, X.; Yang, B.; Song, J.; Zhao, X.; Huang, B.; Shi, W.; Lu, R.; et al. A novel coronavirus from patients with pneumonia in China, 2019. N. Engl. J. Med. 2020, 382, 727-733. [CrossRef] 
3. World Health Organization. Statement on the Second Meeting of the International Health Regulations (2005) Emergency Committee Regarding the Outbreak of Novel Coronavirus (2019-nCoV). Available online: https://www.who.int/news-room/detail/23-01-2020-statement-on-the-meeting-of-the-international-healthregulations-(2005)-emergency-committee-regarding-the-outbreak-of-novel-coronavirus-(2019-ncov) (accessed on 2 February 2020).

4. Lu, H.; Stratton, C.W.; Tang, Y.W. Outbreak of pneumonia of unknown etiology in Wuhan, China: The mystery and the miracle. J. Med. Virol. 2020, 92, 401-402. [CrossRef]

5. Wu, Z.; McGoogan, J.M. Characteristics of and Important Lessons from the Coronavirus Disease 2019 (COVID-19) Outbreak in China: Summary of a Report of 72314 Cases from the Chinese Center for Disease Control and Prevention. JAMA J. Am. Med. Assoc. 2020, 323, 1239-1242. [CrossRef] [PubMed]

6. Koh, D.; Meng, K.L.; Sin, E.C.; Soo, M.K.; Qian, F.; Ng, V.; Ban, H.T.; Kok, S.W.; Wuen, M.C.; Hui, K.T.; et al. Risk perception and impact of severe acute respiratory syndrome (SARS) on work and personal lives of healthcare workers in Singapore: What can we learn? Med. Care 2005, 43, 676-682. [CrossRef] [PubMed]

7. Thombs, B.D.; Bonardi, O.; Rice, D.B.; Boruff, J.T.; Azar, M.; He, C.; Markham, S.; Sun, Y.; Wu, Y.; Krishnan, A. Curating evidence on mental health during COVID-19: A living systematic review. J. Psychosom. Res. 2020, 110113. [CrossRef] [PubMed]

8. Gao, J.; Zheng, P.; Jia, Y.; Chen, H.; Mao, Y.; Chen, S.; Wang, Y.; Fu, H.; Dai, J. Mental health problems and social media exposure during COVID-19 outbreak. PLoS ONE 2020, 15, e0231924. [CrossRef]

9. Choi, E.P.H.; Hui, B.P.H.; Wan, E.Y.F. Depression and Anxiety in Hong Kong during COVID-19. Int. J. Environ. Res. Public Health 2020, 17, 3740. [CrossRef]

10. Lai, J.; Ma, S.; Wang, Y.; Cai, Z.; Hu, J.; Wei, N.; Wu, J.; Du, H.; Chen, T.; Li, R.; et al. Factors Associated with Mental Health Outcomes Among Health Care Workers Exposed to Coronavirus Disease 2019. JAMA Netw. Open 2020, 3, e20397. [CrossRef]

11. Zhang, Y.; Zhang, H.; Ma, X.; Di, Q. Mental Health Problems during the COVID-19 Pandemics and the Mitigation Effects of Exercise: A Longitudinal Study of College Students in China. Int. J. Environ. Res. Public Health 2020, 17, 3722. [CrossRef]

12. Zhang, Y.; Ma, Z.F. Impact of the COVID-19 Pandemic on Mental Health and Quality of Life among Local Residents in Liaoning Province, China: A Cross-Sectional Study. Int. J. Environ. Res. Public Health 2020, 17, 2381. [CrossRef] [PubMed]

13. Gómez-Salgado, J.; Andrés-Villas, M.; Domínguez-Salas, S.; Díaz-Milanés, D.; Ruiz-Frutos, C. Related Health Factors of Psychological Distress during the COVID-19 Pandemic in Spain. Int. J. Environ. Res. Public Health 2020, 17, 3947. [CrossRef] [PubMed]

14. De Leo, D.; Trabucchi, M. COVID-19 and the Fears of Italian Senior Citizens. Int. J. Environ. Res. Public Health 2020, 17, 3572. [CrossRef] [PubMed]

15. Consolo, U.; Bellini, P.; Bencivenni, D.; Iani, C.; Checchi, V. Epidemiological Aspects and Psychological Reactions to COVID-19 of Dental Practitioners in the Northern Italy Districts of Modena and Reggio Emilia. Int. J. Environ. Res. Public Health 2020, 17, 3459. [CrossRef]

16. Madani, A.; Boutebal, S.E.; Bryant, C.R. The Psychological Impact of Confinement Linked to the Coronavirus Epidemic COVID-19 in Algeria. Int. J. Environ. Res. Public Health 2020, 17, 3604. [CrossRef]

17. Christidis, P.; Christodoulou, A. The Predictive Capacity of Air Travel Patterns during the Global Spread of the COVID-19 Pandemic: Risk, Uncertainty and Randomness. Int. J. Environ. Res. Public Health 2020, 17, 3356. [CrossRef]

18. Yang, W.; Deng, M.; Li, C.; Huang, J. Spatio-Temporal Patterns of the 2019-nCoV Epidemic at the County Level in Hubei Province, China. Int. J. Environ. Res. Public Health 2020, 17, 2563. [CrossRef]

19. Zhao, P.; Zhang, N.; Li, Y. A Comparison of Infection Venues of COVID-19 Case Clusters in Northeast China. Int. J. Environ. Res. Public Health 2020, 17, 3955. [CrossRef]

20. Centers for Disease Control and Prevention. Coronavirus Disease 2019: Quarantine and Isolation: How Are Quarantine and Isolation Different? Available online: https://www.cdc.gov/coronavirus/2019-ncov/if-youare-sick/quarantine-isolation.html (accessed on 14 May 2020).

21. Bloomberg Businessweek. Coronavirus Is More Dangerous for the Global Economy Than SARS. Available online: https://www.bloomberg.com/news/articles/2020-01-31/the-coronavirus-is-more-dangerous-for-theeconomy-than-sars (accessed on 1 May 2020). 
22. Meltzer, M.I.; Cox, N.J.; Fukuda, K. The economic impact of pandemic influenza in the United States: Priorities for intervention. Emerg. Infect. Dis. 1999, 5, 659. [CrossRef]

23. Hong, Y.; Cai, G.; Mo, Z.; Gao, W.; Xu, L.; Jiang, Y.; Jiang, J. The Impact of COVID-19 on Tourist Satisfaction with B\&B in Zhejiang, China: An Importance-Performance Analysis. Int. J. Environ. Res. Public Health 2020, 17, 3747. [CrossRef]

24. Zhang, Y.L.; Liang, W.; Chen, Z.M.; Zhang, H.M.; Zhang, J.H.; Weng, X.Q.; Yang, S.C.; Zhang, L.; Shen, L.J.; Zhang, Y.L. Validity and reliability of Patient Health Questionnaire-9 and Patient Health Questionnaire-2 to screen for depression among college students in China. Asia Pac. Psychiatry 2013, 5, 268-275. [CrossRef] [PubMed]

25. He, X.Y.; Li, C.B.; Qian, J.; Cui, H.S.; Wu, W.Y. Reliability and validity of a generalized anxiety scale in general hospital outpatients. Shanghai Arch. Psychiatry 2010, 22, 200-203. [CrossRef]

26. Yu, D.S. Insomnia Severity Index: Psychometric properties with Chinese community-dwelling older people. J. Adv. Nurs. 2010, 66, 2350-2359. [CrossRef] [PubMed]

27. Wu, K.K.; Chan, K.S. The development of the Chinese version of Impact of Event Scale-Revised (CIES-R). Soc. Psychiatry Psychiatr. Epidemiol. 2003, 38, 94-98. [CrossRef]

(C) 2020 by the authors. Licensee MDPI, Basel, Switzerland. This article is an open access article distributed under the terms and conditions of the Creative Commons Attribution (CC BY) license (http://creativecommons.org/licenses/by/4.0/). 